\title{
The Acute Respiratory Distress Syndrome: Diagnosis and Management
}

\section{1}

\author{
Davide Chiumello, Antonella Marino, \\ and Antonio Cammaroto
}

The first of the acute respiratory distress syndrome (ARDS) description was in 1821 by Laennec. Since that many and more accurate definitions followed. Nowadays almost $5 \%$ of hospitalized and mechanically ventilated patients present ARDS diagnostic criteria [1]. ARDS can be generally defined as a new acute onset of hypoxemia and bilateral opacities after an insult direct or indirect to the lungs [2-4]. In 1994 there was the first shared definition, and then, in 2001, an update known as "Berlin definition" was made by an expert panel of the European Society of Intensive Care Medicine [4]. According to this new definition, ARDS is an acute form of diffuse lung injury that happens in patients with predisposing factors, with:

- Symptoms onset within 1 week of a known clinical insult or new or worsening respiratory symptoms

- Bilateral opacities not fully explained by effusions, lobar/lung collapse, or nodules

- Respiratory failure not fully explained by cardiac failure or fluid overload

- Hypoxia, classified by $\mathrm{PaO}_{2} / \mathrm{FiO}_{2}$ ratio measured with at least PEEP of $5 \mathrm{cmH}_{2} \mathrm{O}$ into: mild (200 $\mathrm{mmHg} \leq \mathrm{PaO}_{2} / \mathrm{FiO}_{2} \leq 300 \mathrm{mmHg}$ ), moderate $\left(100 \mathrm{mmHg} \leq \mathrm{PaO}_{2} /\right.$ $\left.\mathrm{FiO}_{2} \leq 200 \mathrm{mmHg}\right)$, severe $\left(\mathrm{PaO}_{2} / \mathrm{FiO}_{2} \leq 100 \mathrm{mmHg}\right)[2-4]$.

This new definition brings a small, but very important, improvement in predictive ability for mortality (Area Under the Curve [AUC] 0.577) [5].

\footnotetext{
D. Chiumello $(\bowtie)$

Intensive Therapy, University of Milan San Paolo Hospital, Milan, Italy

e-mail: davide.chiumello@unimi.it
}

\section{A. Marino}

UOC Anestesia e Rianimazione, Ospedale San Paolo, ASST Santi Paolo e Carlo, Milan, Italy

\footnotetext{
A. Cammaroto

Dipartimento di Fisiopatologia Medico-Chirurgica e dei Trapianti, Università degli Studi di

Milano, Milan, Italy
} 
Recently it has been demonstrated that classifying ARDS severity at a standard level of positive end-expiratory pressure (PEEP) of $5 \mathrm{cmH}_{2} \mathrm{O}$ allows a better alveolar edema and potential of lung recruitment estimation than using higher clinically set PEEP levels [6].

\subsection{Diagnostic Evaluation}

Main ARDS finding is the increased permeability of lung capillaries due to both alveolar epithelium and end vascular endothelium injuries. As consequence a protein-rich fluid accumulates into alveoli, cytokines are released, and a diffuse alveolar injury develops [7]. Alveolar epithelium is composed of type I and II pneumocytes. Injury of type I cells leads to liquid accumulation into alveoli and to a reduction in clearance ability, while injury of type II cells leads to surfactant reduction, alveolar collapse, and lung compliance decrease [5]. ARDS pathological pathway is described as a three-phase process: inflammatory, proliferative, and fibrotic phase with each one that could be stopped or complicated by worsening of patient's symptoms or other complications. Common ARDS risk factors are pneumonia, sepsis, inhalation/aspiration injury, trauma, pancreatitis, burns, non-cardiogenic shock, drowning, and transfusion-related acute lung injury (TRALI) [8]. However, pneumonia is the leading cause of ARDS, so microbiological investigations aiming to pathogen's identification are milestones in the diagnostic process. Communityacquired pneumonia is still the leading cause of ARDS in case of pneumonia etiology [9], while a recent study found that viral pneumonia is becoming more frequent going from $5 \%$ to $10 \%$ [10-12] to $36 \%$. Among viral pneumonia, respiratory virus is predominant [13]; in this case, the first-line diagnostic test is polymerase chain reaction (PCR) test on bronchoalveolar lavage (BAL) [14]. Less frequent ARDS causes are represented by CMV and HSV infections [12, 15] and by parasites (such as Toxoplasma gondii, Aspergillus fumigatus, Pneumocystis jirovecii) mainly present in immunocompromised patients.

Early and correct treatment of the triggering cause appears to be decisive in improving patient's outcome; thus a fast and precise etiological diagnosis is very useful. It is therefore important to first investigate the possible infectious causes by performing blood cultures, urine samples for the detection of Legionella pneumophila's and Streptococcus pneumoniae's antigens, serological tests for the research of Mycoplasma pneumoniae and Chlamydia pneumoniae, and microbiological samples of the respiratory system, preferably performed with BAL [16].

However, it is worth knowing that ARDS without identifiable risk factor have a prevalence of $7.5 \%$ [17]. In this scenario the cytological analysis on BAL sample, chest CT scan, and an immunological evaluation is useful while looking for less common causes. If neither radiological CT images nor alveolar bronchoscopy cytology is decisive, a diagnostic open lung biopsy (OLB) may be done. OLB has also a role in the evaluation of histological lung characteristics evolution, helping the clinician in the decision toward the use or not of corticosteroids [15]. Figure 11.1 represents the diagnostic flowchart in ARDS. Lung CT scan is frequently used to 
Fig. 11.1 Diagnostic flowchart in pulmonary ARDS

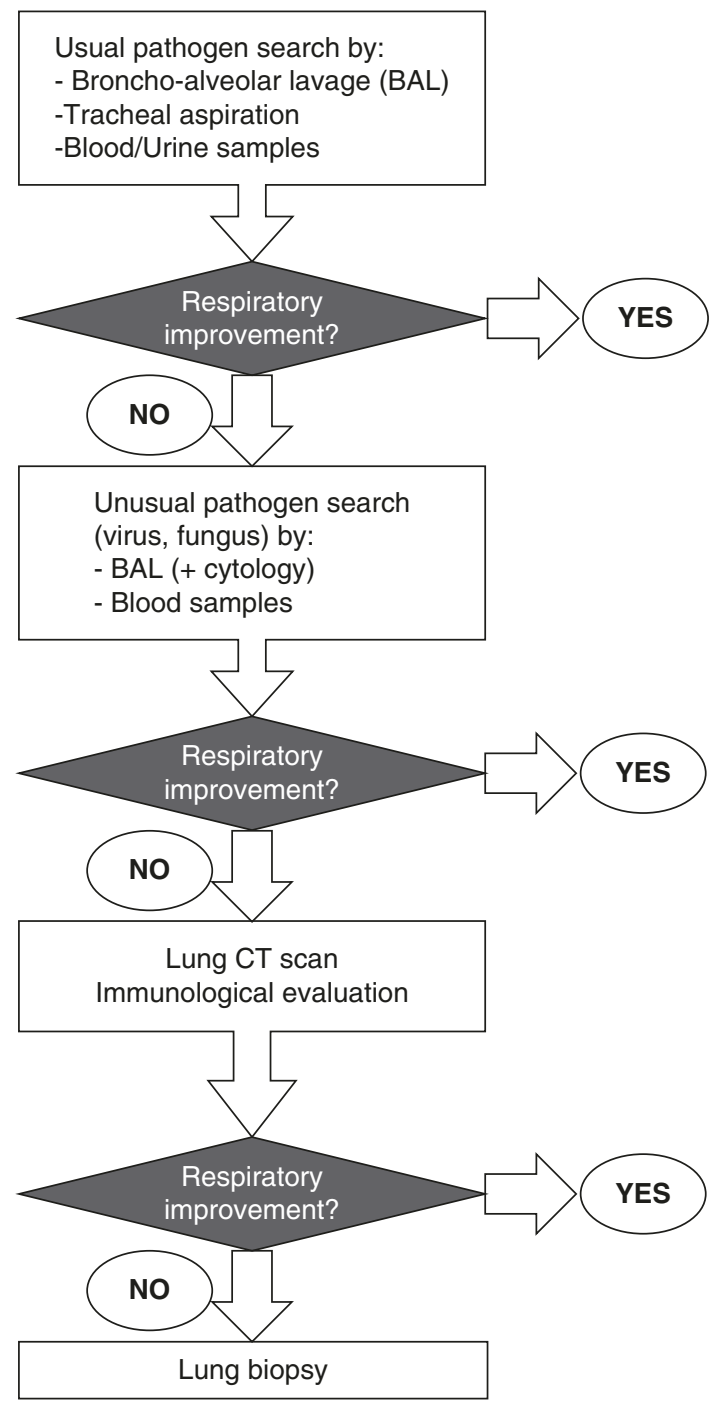

evaluate lung morphology, which in ARDS is characterized by consolidated regions (homogeneous areas with increased density without identifiable vessels or bronchi), ground glass regions (areas with increased density but with still visible vessels), and normally aerated regions. Since lungs are characterized by diffuse edema, with the superimposed pressure causing atelectasis and collapse of dependent lung zones, consolidated areas are typically located in dependent lung regions [18]. Lung CT scan is also helpful in lung potential of recruitment evaluation, i.e., the proportion of consolidated lung that regain aeration after an increase in alveolar pressures. In ARDS patients, potential of recruitment could range between $0 \%$ and $70 \%$. 
Moreover, lung CT scan could help clinician in identifying ARDS etiology; in fact, in pulmonary ARDS consolidated and ground glass areas are similar, while in extrapulmonary ARDS ground glass areas are predominant [19]. Next to CT scan, ultrasound of lung parenchyma, pleura, and air may be helpful in diagnostic evaluation, clinical management, and monitoring of ARDS patients [20-23]. In respiratory failure patients, lung ultrasound is characterized mainly by B-line (hyperechogenic vertical artifact line that starts from pleura) [21], while the B-pattern composed of three or more B-lines appears to be correlated with an interstitial pathological process [24]. A bilateral homogeneous B-pattern is not decisive between ARDS and cardiogenic edema and deserves further analysis [25], while bilateral, nothomogeneous B-pattern plus C-pattern composed of consolidated areas and pleura abnormalities are suggestive of ARDS etiology [26]. Figure 11.2 shows possible lung ultrasound patterns.

\subsection{Treatment}

The acute respiratory failure management includes early recognition of the triggering cause and timely targeted treatment. Besides that, supportive treatments must be started to assure adequate respiratory gas exchange while minimizing the risk of ventilator-induced lung injury (VILI) onset. Actual knowledge suggest that in most severe ARDS patients, spontaneous respiratory triggering could be dangerous; thus the spontaneous breathing approach should be used only in mild and moderate ARDS patients. Different therapeutic targets should be met using different pharmacological and non-pharmacological approaches and different mechanical ventilation modalities.

\subsubsection{Noninvasive Mechanical Ventilation}

Noninvasive mechanical ventilation (NIMV) is able to reduce patient's work of breathing and intrapulmonary shunt, improving gas exchange, avoiding patient's deep sedation, and reducing the ventilator-associated pneumonia risk. However, NIMV use is widely debated due to the high risk of failure (i.e. an intubation rate between $30 \%$ and $86 \%$ and a mortality rate between $15 \%$ and $71 \%$ ) [27], and the consequent risk of delaying intubation and mechanical ventilation in patients who fail this kind of support. High-flow nasal cannula (HFNC) represents an additional noninvasive ventilatory support that ensures patient's administration of a heated and humidified high flow of oxygen through the patient's nose and has shown to be able to reduce respiratory work while improving oxygenation and $\mathrm{CO}_{2}$ elimination, providing the patient with a positive end-expiratory pressure (PEEP) that varies between 4 and $6 \mathrm{cmH}_{2} \mathrm{O}$. A recent study carried out on patients diagnosed with ARDS, as in the case of NIV [28], showed however a high rate of HFNC failure, equal to $40 \%$ [29]. 

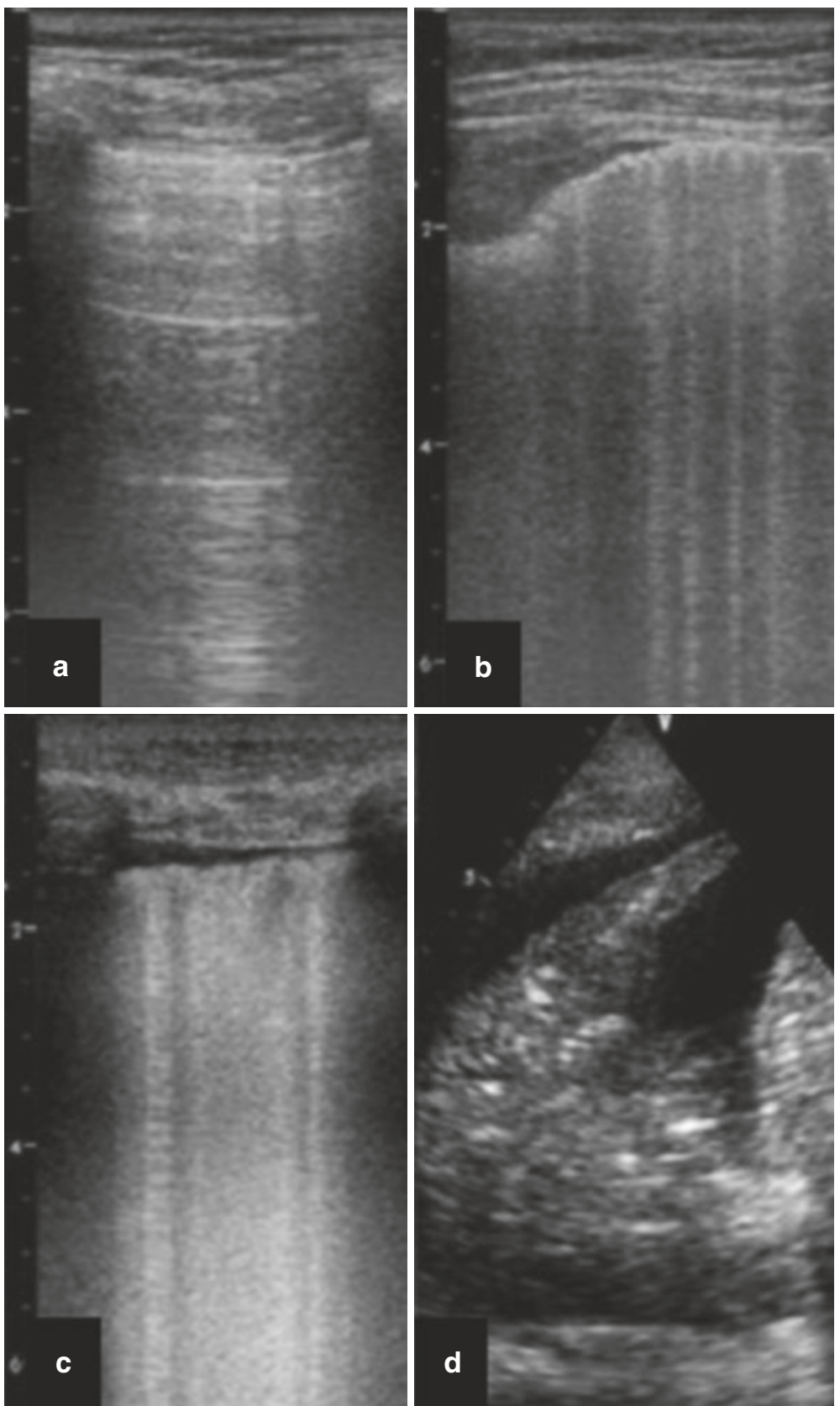

Fig. 11.2 Lung ultrasonographic patterns. Panel $(\mathbf{a})=$ normally aerated lung with pleural sliding $(0$ point $)$. Panel $(\mathbf{b})=$ B-lines separated by at least $5 \mathrm{~mm}(1$ point $)$. Panel $(\mathbf{c})=$ B-lines separated by less than $5 \mathrm{~mm}$ ( 2 points). Panel $(\mathbf{d})=$ consolidated lung, hyperechoic areas, and bronchograms ( 3 points) 


\subsubsection{Invasive Mechanical Ventilation and Pulmonary Recruitment}

Invasive mechanical ventilation is a supportive therapy able to guarantee adequate gas exchange (increase $\mathrm{PaO}_{2}$ and clear $\mathrm{CO}_{2}$ adequately) and reduce the respiratory muscle activity [30]. Mechanical ventilation presents a double effect on patient oxygenation: it allows a continuous and precise $\mathrm{FiO}_{2}$ titration and during the inspiratory phase applies a positive airway pressure that reopens collapsed alveolar units. This second effect is likely to be limited in time, unless an adequate positive endexpiratory pressure is applied during the expiratory phase to avoid the alveolar recollapse [31]. The ventilatory setting in ARDS patient remains a daily challenge, and the choice should be adapted to each patient considering his/her hemodynamic parameters, respiratory mechanics, and gas exchange. During the last 30 years, literature has already widely demonstrated that high-volume/high-frequency ventilation can damage the lungs [32] mainly through the cycling collapse-reopening and alveolar overdistention phenomena that contribute to the so-called atelect-trauma [33]. The application of high PEEP allows collapsed alveoli reopening and intrapulmonary shunt reduction, moreover it reduces the repetitive alveolar opening and closing which occurs during the respiratory cycle [34]. However, it's not always useful to set high PEEP levels, as it could appear at first; indeed, two randomized and controlled trials comparing ARDS patients treated with low vs. high PEEP [35, 36] have not shown any benefit from the use of the high PEEP strategy. These contradictory results can be explained by the pulmonary recruitment concept, i.e., the volume of collapsed pulmonary parenchyma in which is possible to re-establish a normal aeration by an increase in the airway pressure [37]. To recruit collapsed lung regions and keep them open, it is necessary to apply an airway pressure higher enough to counterbalance the superimposed pressure, i.e., the pressure generated by the weight of the lung and the rib cage that acts on the lung below [38]. Several maneuvers can be used to recruit the lung: the sigh (i.e., one high-volume breath intermittently provided by the ventilator), the extended sigh (i.e., a progressive increase in PEEP or a progressive increase in both PEEP and plateau pressure), and the sustained inflation (i.e., a static sustained increase in the airway pressure [35$40 \mathrm{mmHg}$ ] protracted for 20-40 seconds) [39]. The target of these maneuvers is to increase the transpulmonary pressure for a period of time sufficiently long to reinflate the alveolar units previously closed. While these maneuvers are able to improve the oxygenation for a variable period of time, their systematic use did not result in a mortality reduction [40]. While the lung CT scan is the gold standard for the potential of recruitment evaluation, the lung ultrasound seems to be a promising alternative available at the patient's bedside with several advantages such as safety and repeatability; however further studies are necessary to confirm this data [41].

\subsubsection{Choice of PEEP}

As known, the choice of a too low end-expiratory positive pressure could cause the collapse of otherwise recruited parenchymal areas, while the choice of a too high 
end-expiratory positive pressure could increase dead space and tissue stretch thus raising the risk of lung damage. The PEEP optimization is therefore crucial in the individual patient to avoid the continuous opening and closing and the overdistention phenomena in some parenchymal areas. Different approaches have been proposed to choose the best PEEP, but the most commonly used is the one based on the $\mathrm{PEEP} / \mathrm{FiO}_{2}$ table, which use the patient's saturation/oxygenation as target [36]. Another method is based on the respiratory mechanics: PEEP is progressively increased while keeping the tidal volume constant and the airway pressure within a safety range (26-28 $\mathrm{cmH}_{2} \mathrm{O}$ ) [42]. Conversely, our group uses the esophageal pressure variation during the breath, to evaluate the transpulmonary pressure. It is measured as: (plateau pressure - total PEEP) - (esophageal pressure at plateau - esophageal pressure at ZEEP). The transpulmonary pressure is a pulmonary stress indicator, and it should not exceed $15 \mathrm{cmH}_{2} \mathrm{O}$ [43].

\subsubsection{Choice of Tidal Volume}

The main determinants of the ventilator-induced lung injury are strain (defined as the lung deformation induced by the application of the tidal volume) and stress (i.e., the transpulmonary pressure determined by the strain) [44]. Therefore, to maintain low stress and strain, it is necessary to apply a low tidal volume or have a high residual functional capacity $[42,45]$. A recent meta-analysis has shown how the use of "protective ventilation," with a tidal volume of $6 \mathrm{~mL} / \mathrm{kg}$ (calculated on $\mathrm{kg}$ of ideal body weight), guarantees a reduction in mortality [46]. Since the actual body weight isn't an accurate index of lung size, it is recommended the use of the ideal weight (calculated based on gender and height) to calculate the best tidal volume; however, the ideal weight is not correlated with the functional residual capacity of the lung, highlighting that the same tidal volume can generate very different stress and strain values [47] in people with the same gender and height but different functional residual capacity. Amato, in a recent study performed over a group of 3500 patients with ARDS ventilated with different combinations of PEEP and tidal volume, showed that the variable most closely associated with the outcome of patients is represented by the driving pressure of the airways, calculated as (plateau pressure - total PEEP). Furthermore in that study was demonstrated that high levels of PEEP appeared protective only when associated with reduced driving pressure, with a pressure cutoff of $15 \mathrm{cmH}_{2} \mathrm{O}$ [48]. However, the use of driving pressure has several limitations: the main one is the fact that the pressure that extends the lung is the transpulmonary pressure and not the airway pressure.

\subsubsection{Target of Blood Gases}

Current recommendations encourage the use, in mechanically ventilated patients, of a conservative oxygen strategy with an $\mathrm{O}_{2}$ arterial saturation target ranging from $88 \%$ to $95 \%$. The associated use of a "protective ventilation," with the aim of 
reducing the damage induced by ventilation, can however cause the development of hypercapnia; however a $\mathrm{PaCO}_{2}$ around $70 \mathrm{mmHg}$ and a $\mathrm{pH}$ of about 7.20 have been proved to be safe $[49,50]$, except in special cases such as patients with intracranial hypertension or severe heart failure. The rationale for this permissive strategy lies in the known effect that hypercapnic acidosis exerts on arterial and tissue oxygenation [51].

\subsubsection{Neuromuscular Blockade}

In order to guarantee a better patient adaptation to the ventilator, to reduce the oxygen consumption related to the respiratory muscle activity and to guarantee a protective transpulmonary pressure, the use of neuromuscular blockers is accepted in clinical practice [49]. Moreover, neuromuscular blockers have the ability to reduce stress and strain applied to the parenchyma. Neto demonstrated that, in patients with severe ARDS, a short course of treatment with neuromuscular blockers was associated with a mortality decrease [52].

\subsubsection{Prone Positioning}

The indications for the prone positioning have changed over time: once it was used to improve arterial oxygenation in the most severe forms of respiratory failure [53, 54]; while nowadays it aims to achieve a more homogeneous distribution of stress and strain within the lung parenchyma, acting in synergy with the remaining therapies and protecting against the ventilator induced lung injury [55]. The prone positioning improves ventilation/perfusion coupling thus improving the $\mathrm{CO}_{2}$ elimination and improves the ventilation distribution across the dorsal regions of the pulmonary parenchyma $[55,56]$. The association of prone positioning and the use of neuromuscular blockers, in patients with severe ARDS, seems to have a synergistic effect on oxygenation and overall duration of mechanical ventilation and seems to be associated with a better outcome. However, these data needs further studies to confirm.

In any case, the prone positioning presents few absolute contraindications, namely, pregnancy, open abdominal treatment, unstable fractures, and hemodynamic instability [55].

\subsubsection{Corticosteroids and Inhaled Vasodilators}

As shown above, the central role in the pathogenesis of ARDS is played by the inflammatory response that develops in the lung. Several trials have been performed over time to evaluate the use of corticosteroids in the treatment of respiratory distress syndrome, but the results appeared controversial [57, 58]. Meduri in his study carried out in the early phases of the ARDS, showed that the use of a decremental infusion scheme of corticosteroids leads to a mortality reduction in intensive care 
[57]. However, in other studies, this result has not been confirmed [58, 59]. Although nitric oxide (NO) has a known vasodilatory effect on the pulmonary vessels thus ensuring an improvement of the ventilation/perfusion coupling, its use in patients with ARDS is not universally accepted [60]. In fact, it has not been clearly demonstrated its benefit in terms of mortality, while its use is burdened by possible serious complications, such as renal failure [61].

\subsubsection{Extracorporeal Support}

The use of extracorporeal membrane oxygenation (ECMO) in the treatment of severe respiratory failure was born around the 70s with the aim of properly oxygenating the patient ensuring a protective ventilation, reducing the chances of lung damage. Several observational studies have demonstrated various ECMO's benefits in patients with respiratory failure. However, the CESAR study, a recent randomized trial, showed an increase in survival at 6 months (63\% vs. $47 \%$ ) but no difference in quality of life and spirometric parameters between patients undergoing conventional mechanical ventilation and extracorporeal support in reference ECMO centers [62]. Therefore, considering the non-univocal interpretation of the data coming from this trial, nowadays it is not possible to conclude for a superiority of ECMO support compared with the association of the supportive therapy listed above [63].

\subsection{Weaning from Mechanical Ventilation}

It is of crucial importance the choice of the right moment to start the weaning from mechanical ventilation and to extubate the patient: any delay in extubation increases the risk to develop ventilator-associated pneumonia [64]; while a premature extubation can lead to a prolonged stay in ICU [65] and/or to a new need of invasive respiratory support. The weaning from mechanical ventilation is considered difficult in the $20-30 \%$ of mechanical-ventilated patients: the failure of the weaning process is defined as the inability to overcome a spontaneous breathing test or as the need for re-intubation within the first 48 hours from the endotracheal tube removal [66]. The causes of weaning failure are complex and determined by different factors; the main ones are listed below.

\subsubsection{Airways Resistance}

In the patient with a difficult weaning, an increase in the airways resistance should be considered. Moreover, a secondary tracheal obstruction caused by tracheal stenosis, tracheomalacia or the development of granulation tissue, can contribute to a complicated weaning from mechanical ventilation [67]. In ARDS patients an increase in airway resistances is typically due to bronchial walls edema of the small airways. 


\subsubsection{Neurological Alterations}

The delirium seems to be the more frequent neurological alteration associated with a difficult weaning, with a four-time extubation failure rate than a patient without neurological complications [68]. Delirium diagnosis is simple thanks to the use of validates scales, such as CAM-ICU. Psychiatrists and psychologists could be helpful in other cognitive disturbances diagnosis different from delirium. A well-known risk factor for delirium is represented by sedation, in particular when midazolam is used [69]. The implementation of a daily sedative wash-out protocol, possibly together with a spontaneous breathing trial, can be associated to a reduction in ventilatory support length [70]. The depression development, common in patients staying in ICU for long periods, seems to be associated to an increased risk of weaning failure [71]. Antidepressant drugs seem to foster weaning from mechanical ventilation, even if only few data are available at the moment [72].

\subsubsection{Cardiovascular Alterations}

In the patient affected by an alteration of the myocardial contractility, the shift from mechanical ventilation to spontaneous breathing causes an increase in the cardiovascular work, mainly due to two factors: an intrathoracic pressure variation that causes changes in preload and afterload and an increase of the oxygen consumption by respiratory muscles [73]. An accurate cardiovascular evaluation in mechanically ventilated patients makes the introduction or the optimization of the appropriate therapy possible: this allows a reduction of the weaning failure risk.

\subsubsection{Diaphragmatic and Respiratory Musculature Function}

The beginning of weaning causes an increase in respiratory muscle workload that frequently appears to be already weakened. In assessing the cause of muscle weakness, it is important to bear in mind that the respiratory muscle dysfunction can result from a damage located anywhere on the axis from the afferent chemoreceptors, to the respiratory center, to the single muscle fiber [73].

The cause of the failure is frequently represented by a diaphragm alteration that can be secondary to two conditions that often coexist in the same patient: the critical illness polyneuropathy (CIP) involving the phrenic nerve and, more often, the critical illness myopathy (CIM). Several works have demonstrated that in mechanicalventilated patients, there is often an alteration of the respiratory muscle contractility [74]. Before implementing weaning-from-mechanical-ventilation protocols, it is necessary to carefully assess the diaphragmatic function so as to exclude the presence of alterations. To do so, some tests used in clinical practice are here below displayed.

- $P_{0.1}$ : it is the most frequently used test for the respiratory drive evaluation in mechanically ventilated patients. In order to carry out this test, the ventilator's 
inspiratory valve is closed, and the pressure fall within the first $100 \mathrm{msec}$ after the patient's inspiratory attempt is recorded. Usually, the $P_{0.1}$ value varies between 0.5 and $1.5 \mathrm{cmH}_{2} \mathrm{O}$. It is important to note that this parameter depends both on the inspiratory muscular strength and on the respiratory drive.

- Maximal inspiratory pressure (MIP): represents the maximum pressure that the patient can generate by inhaling against a completely occluded airway, starting from functional residual capacity (FRC). The minimum thresholds are $-75 \mathrm{cmH}_{2} \mathrm{O}$ for men and $-50 \mathrm{cmH}_{2} \mathrm{O}$ for women [75]. Theoretically, the most negative values exclude the presence of a significant muscular weakness.

- Rapid shallow breathing index (RSBI): introduced by Tobin [76], it is one of the most common indexes used to evaluate patients in weaning process. It is defined as the ratio between the respiratory rate and the tidal volume expressed in liter. Patients that tend to breathe with a higher respiratory rate and with a smaller tidal volume have a high RSBI and more probably a higher risk of weaning failure. The majority part of centers considers a RSBI $<105$ adequate to start weaning the patient from mechanical ventilation [77].

Mechanical ventilation is a life-saving intervention in patients affected by acute respiratory distress, but it is also associated with complications. Therefore it is desirable to wean patients from mechanical ventilation as soon as the underlying cause that led to the need for ventilatory support is resolved or the patient has sufficiently improved and is able to sustain spontaneous breathing with adequate respiratory mechanics and gas exchange. Recently, there were published some guidelines aimed at giving indications on which weaning/extubation techniques it is recommended to use in patients under mechanical ventilation [78]:

- For acutely hospitalized patients ventilated more than $24 \mathrm{~h}$ who are able to make a weaning attempt, it is recommended to carry out an initial spontaneous breathing trial with inspiratory pressure support $\left(5-8 \mathrm{cmH}_{2} \mathrm{O}\right)$.

- For acutely hospitalized patients ventilated for more than $24 \mathrm{~h}$, it is suggested to use protocols to minimize sedation or guarantee sedative suspension periods, during which carry out a spontaneous breathing trial.

- For acutely hospitalized patients ventilated more than $24 \mathrm{~h}$ at high risk for extubation failure and who have passed a spontaneous breathing trial, it is recommended the application of noninvasive ventilation (NIV) following extubation.

\subsection{Conclusions}

Still today, ARDS represents a syndrome with a globally high incidence and a high mortality rate that varies between $40 \%$ and $60 \%$. The use of a systematic diagnostic approach can help physicians to rapidly identify the triggering cause of the syndrome, making it possible to quickly start with the right therapy. Chest imaging, mainly represented by CT scan, is of primary relevance both in the diagnostic pathway and in the evaluation of lung parenchyma recruitability. The use of lung ultrasound is gaining a pivotal role in the daily bedside evaluation of the patient, thanks 
to its role in the differential diagnosis and to the possibility to evaluate right and left ventricular function. The supportive treatment guaranteed to patients with respiratory distress needs to be oriented to the maintenance of vital functions, to the improvement of gas exchange and to the reduction of lung injury risk.

In order to avoid ventilator-induced lung injury and to set a lung protective ventilation, it is useful to monitor functional residual capacity (FRC) and transpulmonary pressure.

In the most severe cases, it can be useful to use neuromuscular-blocking drugs and prone position so as to improve ventilation/perfusion ratio. Another challenge for physicians seems to be the weaning from mechanical ventilation: the aim is to exclude all the alterations that may delay or make fail the respiratory weaning. The latest guidelines written by the American Thoracic Society and the American College of Chest Physicians are useful to treat the patient in this crucial phase.

\section{References}

1. Esteban A, Ferguson ND, Meade MO, Frutos-Vivar F, Apezteguia C, Brochard L, et al. Evolution of mechanical ventilation in response to clinical research. Am J Respir Crit Care Med. 2008;177(2):170-7.

2. Ashbaugh DG, Bigelow DB, Petty TL, Levine BE. Acute respiratory distress in adults. Lancet. 1967;2(7511):319-23.

3. Bernard GR, Artigas A, Brigham KL, Carlet J, Falke K, Hudson L, et al. The AmericanEuropean Consensus Conference on ARDS. Definitions, mechanisms, relevant outcomes, and clinical trial coordination. Am J Respir Crit Care Med. 1994;149(3 Pt 1):818-24.

4. Ranieri VM, Rubenfeld GD, Thompson BT, Ferguson ND, Caldwell E, Fan E, et al. Acute respiratory distress syndrome: the Berlin Definition. JAMA. 2012;307(23):2526-33.

5. Umbrello M, Formenti P, Bolgiaghi L, Chiumello D. Current concepts of ARDS: a narrative review. Int J Mol Sci. 2016;18(1):pii: E64.

6. Caironi P, Carlesso E, Cressoni M, Chiumello D, Moerer O, Chiurazzi C, et al. Lung recruitability is better estimated according to the Berlin definition of acute respiratory distress syndrome at standard $5 \mathrm{~cm} \mathrm{H} 2 \mathrm{O}$ rather than higher positive end-expiratory pressure: a retrospective cohort study. Crit Care Med. 2015;43(4):781-90.

7. Martin TR. Lung cytokines and ARDS: Roger S. Mitchell lecture. Chest. 1999;116(1 Suppl):2S-8S.

8. Ferguson ND, Fan E, Camporota L, Antonelli M, Anzueto A, Beale R, et al. The Berlin definition of ARDS: an expanded rationale, justification, and supplementary material. Intensive Care Med. 2012;38(10):1573-82.

9. Piantadosi CA, Schwartz DA. The acute respiratory distress syndrome. Ann Intern Med. 2004;141(6):460-70.

10. de Roux A, Marcos MA, Garcia E, Mensa J, Ewig S, Lode H, et al. Viral community-acquired pneumonia in non immunocompromised adults. Chest. 2004;125(4):1343-51.

11. Jennings LC, Anderson TP, Beynon KA, Chua A, Laing RT, Werno AM, et al. Incidence and characteristics of viral community-acquired pneumonia in adults. Thorax. 2008;63(1):42-8.

12. Luyt CE, Combes A, Trouillet JL, Nieszkowska A, Chastre J. Virus-induced acute respiratory distress syndrome: epidemiology, management and outcome. Presse Med. 2011;40(12 Pt 2):e561-8.

13. Choi SH, Hong SB, Ko GB, Lee Y, Park HJ, Park SY, et al. Viral infection in patients with severe pneumonia requiring intensive care unit admission. Am J Respir Crit Care Med. 2012;186(4):325-32. 
14. Bautista E, Chotpitayasunondh T, Gao Z, Harper SA, Shaw M, Uyeki TM, et al. Clinical aspects of pandemic 2009 influenza A (H1N1) virus infection. N Engl J Med. 2010;362(18):1708-19.

15. Papazian L, Calfee CS, Chiumello D, Luyt CE, Meyer NJ, Sekiguchi H, et al. Diagnostic workup for ARDS patients. Intensive Care Med. 2016;42(5):674-85.

16. Gadsby NJ, Helgason KO, Dickson EM, Mills JM, Lindsay DS, Edwards GF, et al. Molecular diagnosis of legionella infections--clinical utility of front-line screening as part of a pneumonia diagnostic algorithm. J Infect. 2016;72(2):161-70.

17. Gibelin A, Parrot A, Maitre B, Brun-Buisson C, Mekontso Dessap A, Fartoukh M, et al. Acute respiratory distress syndrome mimickers lacking common risk factors of the Berlin definition. Intensive Care Med. 2016;42(2):164-72.

18. Pelosi P, D'Andrea L, Vitale G, Pesenti A, Gattinoni L. Vertical gradient of regional lung inflation in adult respiratory distress syndrome. Am J Respir Crit Care Med. 1994;149(1):8-13.

19. Goodman LR, Fumagalli R, Tagliabue P, Tagliabue M, Ferrario M, Gattinoni L, et al. Adult respiratory distress syndrome due to pulmonary and extrapulmonary causes: $\mathrm{CT}$, clinical, and functional correlations. Radiology. 1999;213(2):545-52.

20. Lichtenstein DA. Ultrasound in the management of thoracic disease. Crit Care Med. 2007;35(5 Suppl):S250-61.

21. Volpicelli G, Elbarbary M, Blaivas M, Lichtenstein DA, Mathis G, Kirkpatrick AW, et al. International evidence-based recommendations for point-of-care lung ultrasound. Intensive Care Med. 2012;38(4):577-91.

22. Bouhemad B, Liu ZH, Arbelot C, Zhang M, Ferarri F, Le-Guen M, et al. Ultrasound assessment of antibiotic-induced pulmonary reaeration in ventilator-associated pneumonia. Crit Care Med. 2010;38(1):84-92.

23. Peris A, Zagli G, Barbani F, Tutino L, Biondi S, di Valvasone S, et al. The value of lung ultrasound monitoring in H1N1 acute respiratory distress syndrome. Anaesthesia. 2010;65(3):294-7.

24. Lichtenstein DA, Meziere GA. Relevance of lung ultrasound in the diagnosis of acute respiratory failure: the BLUE protocol. Chest. 2008;134(1):117-25.

25. Gargani L, Lionetti V, Di Cristofano C, Bevilacqua G, Recchia FA, Picano E. Early detection of acute lung injury uncoupled to hypoxemia in pigs using ultrasound lung comets. Crit Care Med. 2007;35(12):2769-74.

26. Copetti R, Soldati G, Copetti P. Chest sonography: a useful tool to differentiate acute cardiogenic pulmonary edema from acute respiratory distress syndrome. Cardiovasc Ultrasound. 2008;6:16.

27. Agarwal R, Aggarwal AN, Gupta D. Role of noninvasive ventilation in acute lung injury/acute respiratory distress syndrome: a proportion meta-analysis. Respir Care. 2010;55(12):1653-60.

28. Antonelli M, Conti G, Moro ML, Esquinas A, Gonzalez-Diaz G, Confalonieri M, et al. Predictors of failure of noninvasive positive pressure ventilation in patients with acute hypoxemic respiratory failure: a multi-center study. Intensive Care Med. 2001;27(11):1718-28.

29. Messika J, Ben Ahmed K, Gaudry S, Miguel-Montanes R, Rafat C, Sztrymf B, et al. Use of high-flow nasal cannula oxygen therapy in subjects with ARDS: a 1-year observational study. Respir Care. 2015;60(2):162-9.

30. Gattinoni L. Ultra-protective ventilation and hypoxemia. Crit Care. 2016;20(1):130.

31. Pelosi P, Goldner M, McKibben A, Adams A, Eccher G, Caironi P, et al. Recruitment and derecruitment during acute respiratory failure: an experimental study. Am J Respir Crit Care Med. 2001;164(1):122-30.

32. Webb HH, Tierney DF. Experimental pulmonary edema due to intermittent positive pressure ventilation with high inflation pressures. Protection by positive end-expiratory pressure. Am Rev Respir Dis. 1974;110(5):556-65.

33. Slutsky AS, Tremblay LN. Multiple system organ failure. Is mechanical ventilation a contributing factor? Am J Respir Crit Care Med. 1998;157(6 Pt 1):1721-5.

34. Caironi P, Cressoni M, Chiumello D, Ranieri M, Quintel M, Russo SG, et al. Lung opening and closing during ventilation of acute respiratory distress syndrome. Am J Respir Crit Care Med. 2010;181(6):578-86. 
35. Brower RG, Lanken PN, MacIntyre N, Matthay MA, Morris A, Ancukiewicz M, et al. Higher versus lower positive end-expiratory pressures in patients with the acute respiratory distress syndrome. N Engl J Med. 2004;351(4):327-36.

36. Meade MO, Cook DJ, Guyatt GH, Slutsky AS, Arabi YM, Cooper DJ, et al. Ventilation strategy using low tidal volumes, recruitment maneuvers, and high positive end-expiratory pressure for acute lung injury and acute respiratory distress syndrome: a randomized controlled trial. JAMA. 2008;299(6):637-45.

37. Chiumello D, Marino A, Brioni M, Cigada I, Menga F, Colombo A, et al. Lung recruitment assessed by respiratory mechanics and computed tomography in patients with acute respiratory distress syndrome. what is the relationship? Am J Respir Crit Care Med. 2016;193(11):1254-63.

38. Cressoni M, Chiumello D, Carlesso E, Chiurazzi C, Amini M, Brioni M, et al. Compressive forces and computed tomography-derived positive end-expiratory pressure in acute respiratory distress syndrome. Anesthesiology. 2014;121(3):572-81.

39. Chiumello D, Algieri I, Grasso S, Terragni P, Pelosi P. Recruitment maneuvers in acute respiratory distress syndrome and during general anesthesia. Minerva Anestesiol. 2016;82(2):210-20.

40. Suzumura EA, Figueiro M, Normilio-Silva K, Laranjeira L, Oliveira C, Buehler AM, et al. Effects of alveolar recruitment maneuvers on clinical outcomes in patients with acute respiratory distress syndrome: a systematic review and meta-analysis. Intensive Care Med. 2014;40(9):1227-40.

41. Bouhemad B, Brisson H, Le-Guen M, Arbelot C, Lu Q, Rouby JJ. Bedside ultrasound assessment of positive end-expiratory pressure-induced lung recruitment. Am J Respir Crit Care Med. 2011;183(3):341-7.

42. Protti A, Cressoni M, Santini A, Langer T, Mietto C, Febres D, et al. Lung stress and strain during mechanical ventilation: any safe threshold? Am J Respir Crit Care Med. 2011;183(10):1354-62.

43. Chiumello D, Langer T, Vecchi V, Luoni S, Colombo A, Brioni M, et al. Low-dose chest computed tomography for quantitative and visual anatomical analysis in patients with acute respiratory distress syndrome. Intensive Care Med. 2014;40(5):691-9.

44. Gattinoni L, Carlesso E, Caironi P. Stress and strain within the lung. Curr Opin Crit Care. 2012;18(1):42-7.

45. Chiumello D, Cressoni M, Colombo A, Babini G, Brioni M, Crimella F, et al. The assessment of transpulmonary pressure in mechanically ventilated ARDS patients. Intensive Care Med. 2014;40(11):1670-8.

46. Petrucci N, De Feo C. Lung protective ventilation strategy for the acute respiratory distress syndrome. Cochrane Database Syst Rev. 2013;(2):CD003844.

47. Chiumello D, Carlesso E, Cadringher P, Caironi P, Valenza F, Polli F, et al. Lung stress and strain during mechanical ventilation for acute respiratory distress syndrome. Am J Respir Crit Care Med. 2008;178(4):346-55.

48. Amato MB, Meade MO, Slutsky AS, Brochard L, Costa EL, Schoenfeld DA, et al. Driving pressure and survival in the acute respiratory distress syndrome. $\mathrm{N}$ Engl J Med. 2015;372(8):747-55.

49. Hraiech S, Yoshida T, Papazian L. Balancing neuromuscular blockade versus preserved muscle activity. Curr Opin Crit Care. 2015;21(1):26-33.

50. Hickling KG, Walsh J, Henderson S, Jackson R. Low mortality rate in adult respiratory distress syndrome using low-volume, pressure-limited ventilation with permissive hypercapnia: a prospective study. Crit Care Med. 1994;22(10):1568-78.

51. Caironi P. Driving pressure and intraoperative protective ventilation. Lancet Respir Med. 2016;4(4):243-5.

52. Neto AS, Pereira VG, Esposito DC, Damasceno MC, Schultz MJ. Neuromuscular blocking agents in patients with acute respiratory distress syndrome: a summary of the current evidence from three randomized controlled trials. Ann Intensive Care. 2012;2(1):33.

53. Langer M, Mascheroni D, Marcolin R, Gattinoni L. The prone position in ARDS patients. A clinical study. Chest. 1988;94(1):103-7. 
54. Piehl MA, Brown RS. Use of extreme position changes in acute respiratory failure. Crit Care Med. 1976;4(1):13-4.

55. Gattinoni L, Taccone P, Carlesso E, Marini JJ. Prone position in acute respiratory distress syndrome. Rationale, indications, and limits. Am J Respir Crit Care Med. 2013;188(11):1286-93.

56. Guerin C, Mancebo J. Prone positioning and neuromuscular blocking agents are part of standard care in severe ARDS patients: yes. Intensive Care Med. 2015;41(12):2195-7.

57. Meduri GU, Headley AS, Golden E, Carson SJ, Umberger RA, Kelso T, et al. Effect of prolonged methylprednisolone therapy in unresolving acute respiratory distress syndrome: a randomized controlled trial. JAMA. 1998;280(2):159-65.

58. Steinberg KP, Hudson LD, Goodman RB, Hough CL, Lanken PN, Hyzy R, et al. Efficacy and safety of corticosteroids for persistent acute respiratory distress syndrome. N Engl J Med. 2006;354(16): 1671-84.

59. Bernard GR, Luce JM, Sprung CL, Rinaldo JE, Tate RM, Sibbald WJ, et al. High-dose corticosteroids in patients with the adult respiratory distress syndrome. N Engl J Med. 1987;317(25):1565-70.

60. Siobal MS. Pulmonary vasodilators. Respir Care. 2007;52(7):885-99.

61. Adhikari NK, Dellinger RP, Lundin S, Payen D, Vallet B, Gerlach H, et al. Inhaled nitric oxide does not reduce mortality in patients with acute respiratory distress syndrome regardless of severity: systematic review and meta-analysis. Crit Care Med. 2014;42(2):404-12.

62. Peek GJ, Mugford M, Tiruvoipati R, Wilson A, Allen E, Thalanany MM, et al. Efficacy and economic assessment of conventional ventilatory support versus extracorporeal membrane oxygenation for severe adult respiratory failure (CESAR): a multicentre randomised controlled trial. Lancet. 2009;374(9698):1351-63.

63. Ventetuolo CE, Muratore CS. Extracorporeal life support in critically ill adults. Am J Respir Crit Care Med. 2014;190(5):497-508.

64. Krieger BP. Respiratory failure in the elderly. Clin Geriatr Med. 1994;10(1):103-19.

65. Epstein SK, Ciubotaru RL, Wong JB. Effect of failed extubation on the outcome of mechanical ventilation. Chest. 1997;112(1):186-92.

66. Boles JM, Bion J, Connors A, Herridge M, Marsh B, Melot C, et al. Weaning from mechanical ventilation. Eur Respir J. 2007;29(5):1033-56.

67. Rumbak MJ, Walsh FW, Anderson WM, Rolfe MW, Solomon DA. Significant tracheal obstruction causing failure to wean in patients requiring prolonged mechanical ventilation: a forgotten complication of long-term mechanical ventilation. Chest. 1999;115(4):1092-5.

68. Salam A, Tilluckdharry L, Amoateng-Adjepong Y, Manthous CA. Neurologic status, cough, secretions and extubation outcomes. Intensive Care Med. 2004;30(7):1334-9.

69. Marcantonio ER, Goldman L, Mangione CM, Ludwig LE, Muraca B, Haslauer CM, et al. A clinical prediction rule for delirium after elective noncardiac surgery. JAMA. 1994;271(2):134-9.

70. Girard TD, Kress JP, Fuchs BD, Thomason JW, Schweickert WD, Pun BT, et al. Efficacy and safety of a paired sedation and ventilator weaning protocol for mechanically ventilated patients in intensive care (A wakening and Breathing Controlled trial): a randomised controlled trial. Lancet. 2008;371(9607):126-34.

71. Jubran A, Lawm G, Kelly J, Duffner LA, Gungor G, Collins EG, et al. Depressive disorders during weaning from prolonged mechanical ventilation. Intensive Care Med. 2010;36(5):828-35.

72. Rothenhausler HB, Ehrentraut S, von Degenfeld G, Weis M, Tichy M, Kilger E, et al. Treatment of depression with methylphenidate in patients difficult to wean from mechanical ventilation in the intensive care unit. J Clin Psychiatry. 2000;61(10):750-5.

73. Heunks LM, van der Hoeven JG. Clinical review: the ABC of weaning failure--a structured approach. Crit Care. 2010;14(6):245.

74. Laghi F, Cattapan SE, Jubran A, Parthasarathy S, Warshawsky P, Choi YS, et al. Is weaning failure caused by low-frequency fatigue of the diaphragm? Am J Respir Crit Care Med. 2003;167(2):120-7.

75. Black LF, Hyatt RE. Maximal respiratory pressures: normal values and relationship to age and sex. Am Rev Respir Dis. 1969;99(5):696-702. 
76. Yang KL, Tobin MJ. A prospective study of indexes predicting the outcome of trials of weaning from mechanical ventilation. N Engl J Med. 1991;324(21):1445-50.

77. Ely EW, Baker AM, Dunagan DP, Burke HL, Smith AC, Kelly PT, et al. Effect on the duration of mechanical ventilation of identifying patients capable of breathing spontaneously. N Engl J Med. 1996;335(25):1864-9.

78. Ouellette DR, Patel S, Girard TD, Morris PE, Schmidt GA, Truwit JD, et al. Liberation from mechanical ventilation in critically ill adults: an official American College of Chest Physicians/ American Thoracic Society clinical practice guideline: inspiratory pressure augmentation during spontaneous breathing trials, protocols minimizing sedation, and noninvasive ventilation immediately after extubation. Chest. 2017;151(1):166-80. 